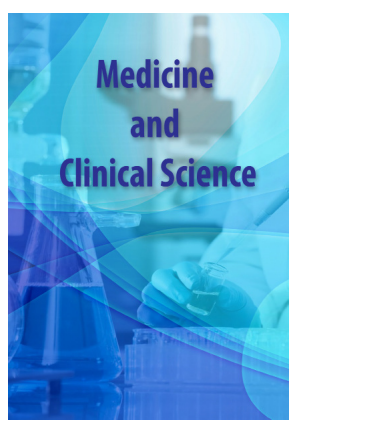

Correspondence

Dr. François Verdon

Escalier du Suchiez 34, 2000 Neuchâtel, Switzerland; Tel: +417993111 65;

E-mail: flverdon@net2000.ch

- Received Date: 25 May 2020;

- Accepted Date: 05 June 2020;

- Publication Date: 24 June 2020.

\section{Keywords}

Clinical Decision-Making; Cognitive function Diagnostic procedure; Early Diagnosis; Intuition; Internal medicine

Copyright

(C) 2020 Science Excel. This is an openaccess article distributed under the terms of the Creative Commons Attribution 4.0 International license.

\title{
Intuitive, analytical and paraclinical approach to the diagnosis in ambulatory medicine
}

\section{François Verdon}

MD, Retired Physician, FMH Internal Medicine

Formerly Assistant Physician, Department of Ambulatory Care and Community Medicine, University of Lausanne, Switzerland Member of the Institute of General Medicine, Rue du Bugnon 44, 1011, Lausanne, University of Lausanne, Switzerland

\begin{abstract}
Objective: Analyse on the spot the principal determinants of diagnostic process in primary care. Methods: In a multicenter observational study, 59 experienced GP evaluated the potential threat of the clinical condition and their diagnostic hypotheses in 672 consecutive patients with chest pain during the initial consultation, after three months and after one year.

Results: One or two minutes after the recognition of chest pain, the GPs offered an assessment of the potential danger in $85 \%$ of patients. The cases assessed as potentially dangerous led to aggressive diagnostic strategies. The diagnostic procedure was consistent from one GP to another and started very quickly during the consultation with proposed diagnostic hypotheses in $70 \%$ after one minute. This initial impression was often modified subsequently so that the final diagnosis was reached in $51 \%$ of cases after one to two minutes, in $81 \%$ at the end of the consultation and in $97 \%$ after one year. Diagnostic tests or referral to a specialist were required in half of all patients. The difficulty of diagnosis and the degree of anxiety of the patients and GPs delayed the diagnostic. Irrational factors such as personality, anxiety or gender of the physician and of the patient influenced the approach. This one seems linked to an intellectual endeavour appeared very early in the human evolution. Conclusion: In primary care, the diagnostic process quickly starts with the assessment of risk associated with the condition and the laying of first diagnostic hypothesis. This intuitive process is followed by an analytical activity based on clinical and, if necessary, paraclinical data. It is mainly founded on the clinic.
\end{abstract}

\section{Introduction}

In medical schools and in teaching hospitals or when complex cases are reported in medical journals, the diagnostic approach is considered as an analytical (or hypothetical-deductive) process using epidemiological, clinical and laboratory data [1]. Emergency medicine does often provide algorithms based largely on paraclinical data for definite clinical status [2]. In general practice, the process of making a diagnosis does follow other poorly understood pathways. General practitioners (GPs) are required to identify serious conditions but must also face all problems, including benign conditions that may still be important for the patient. For GPs, there is very little useful data established on evidencebased medicine $[3,4]$. GPs have acknowledged using non-specific signs $[5,6]$. An early intuitive diagnostic impression could also play a role [7]. However the importance of these phenomena has never been quantified. We approached this diagnostic procedure in outpatients complaining of chest pain. Chest pain is a good subject for study because of its high prevalence but also the variable etiology ranging from harmless to potentially life-threatening. This study evaluates the importance of intuitive, analytical, clinical and paraclinical elements.

\section{Methods}

\section{Setting}

GP-researchers in family medicine associated with an academic primary care department chose chest pain as a research object. They opted for a no-invasive observational study through questionnaires, set up a network of family practitioners, and organised the study with three objectives:

- defining the epidemiology of chest pain in an ambulatory setting,

- defining the clinical markers of the different clinical conditions causing chest pain

- studying the diagnostic process. This later is considered here.

Data collection took place in years 2001-2002 and the very large database was reviewed and analysed until 2005.

\section{Design}

The research network of 59 family practitioners evaluated the diagnostic process in 672 patients consulting their doctors for chest pain. They evaluate the approach 1) at the first encounter after each step of consultation: the initial appraisal, 
history, physical examination and at the end of the encounter 2) at three months, when the majority of even complex cases have found a solution and 3) at twelve months, in light of the evolution data and possible new investigations and new treatments.

\section{General practitioners}

Fifty-eight participating GPs working in private in the French part of Switzerland were included, as well as six residents of an academic primary care outpatient department counted globally as one additional GP. They were not randomised but joined after personal contacts and participated without remuneration. The practices were located in both urban (37 GPs) and non-urban areas, relatively close to an emergency centre. Nine female and 49 male GPs took part to the study.

Their average experience in private practices was 12 years following 7-11 years of postgraduate hospital training. They received detailed information on the study and were trained to fill in the forms. GPs had to handle medical decision in their usual way, without external intervention. Most participants did practice in their office electrocardiograms and emergency laboratory tests. They were free to require more specific tests and to ask for specialist consultation.

\section{Patients}

GPs consecutively enrolled all patients over sixteen years of age who reported any type of chest pain during their visits as a main or minor medical complaint over a three- to nine-week period (median, five weeks) from March to May 2001. Patients were seen by their physician at day one with a control planned for at three and at twelve months. Patients participated willingly and each patient gave informed consent.

\section{General data}

Physicians recorded their observations and their first diagnostic hypothesis on questionnaires validated in a pilot study. All questionnaires were filled immediately after identifying a complaint of chest pain and after each step of consultation. This initial form reported general patient data and characteristics of chest pain. Detailed history, physical examination, level of anxiety expressed by patients and physicians were reported with possible emergency tests results, comorbidities, medication and treatment decision at the end of the consultation, decision to refer the patient to a specialist or hospitalisation. Questionnaires at 3 months evaluated investigations, treatment, and evolution. After twelve months, an ambulatory checkup examination was performed or, by default, a telephone interview was made (13\% patients).

\section{Specific data for diagnostic formation}

The potentially serious nature of the condition and the suspected diagnosis were noted at the different steps of the consultation, and at three months. At twelve months, the evolution, new diagnosis if any, final diagnosis, and degree of certainty were recorded.

\section{Data processing}

All completed forms were sent to the study coordination centre. A set of predefined criteria was used for data entry checks and double data entry was used to identify transcription errors. Inconsistencies or missing data were reported to the principle investigators, who contacted physicians for case resolution. Data cleaning and validation was performed by a group of physicians experienced in research.

We used the diagnosis retained after one year of follow-up as the definite diagnosis. Forty-three patients were lost to follow-up. For the 25 patients deceased, the diagnosis at the time of death was used. For the 18 other patients lost to follow-up, the three-month diagnosis was considered the final diagnosis. When the diagnosis reported by the family practitioner was not consistent throughout the year of follow-up, it was discussed and approved by a group of independent clinicians.

\section{Statistical methods}

The t-test was used for continuous variables, and the chi-square test for data expressed as proportions. All statistical analyses were performed with Statview 5.0 or Stata 7.0 and CIA 2.1.3 for confidence intervals or predictive values calculation. Factors significantly implicated in the diagnosis process were identified in an univariate analysis.

To determine independent indicators, these factors were introduced in a multivariate logistic regression and the influence of clinical factors was given by the pseudo R-squared of the logistic regression. Homogeneity of emergency identification and of diagnosis timing across GPs was verified by one-way ANOVA. Hastiness of evaluation of the risk, early diagnostic guess, and retained diagnosis was compared between the diagnostic classes with the non-parametric Mann-Whitney U test; significance level was set at $\mathrm{p}<0.05$.

\section{Results}

Categories of chest pain, potentially life threatening condition and complex diagnosis are reported in Table 1.

\section{Identification of danger}

The assessment of the potential risk of the disease was made in $85 \%$ of patients one to two minutes after the pain complaint. The condition was considered serious in 162 patients, benign in 409 and uncertain in 101 patients. The 162 patients suspected of a serious condition included 95 of the 134 patients confirmed as severe at one year (Positive Predictive Value 0.59; Negative Predictive Value 0.92). At the end of the consultation, a serious condition was considered in 142 patients including 113 of these 134 patients (PPV 0.80; NPV 0.96). The disquietude of physicians for 99 patients was correlated with a diagnosis of gravity $(r=0.33)$. In contrast, the anxiety expressed by 381 patients was not $(\mathrm{r}=0.03)$.

\section{Timing of diagnosis hypothesis}

Figure 1 reports the diagnosis guess (white columns) at different times of the first encounter, and at three months. One to two minutes after the description of pain, the physicians reported a specific early diagnosis guess for 472 patients (70.2\%); they did not report a diagnostic guess in 200 patients. The diagnostic prevision improved after history, after physical examination and at the end of the first visit with a cumulative guess diagnosis for $97.5 \%$, and $99.1 \%$ at three month. As for identification of danger, the first diagnostic hypothesis was made later when the patients were anxious, and more quickly by women physicians than by men.

\section{Timing of retained diagnosis}

The initial assumptions have been changed up to one year 217 times in 178 of 672 patients (26.5\%) (Figure 1, columns grayed). In view of these changes the final confirmed diagnosis was made after the first minutes in $50.9 \%$ of patients. The diagnostic accuracy improved after history, after physical examination and at the end of the visit with a cumulative specific diagnosis for $80.9 \%$, and $93.8 \%$ for up to three months (Figure 1, black columns).

At the end of the consultation, the diagnosis was less frequently made for complex diagnoses, for older age of the patient, for unknown patient, in the presence of psychiatric comorbidity and when the doctor felt anxiety.

\section{Diagnosis consistency among GPs}

There were no important discrepancies among the 59 participating doctors in evaluating the danger facing the patient. It was formulated within one minute in the five groups significantly faster, at the beginning of history in the forty average groups, and at the end of history in the six groups significantly slower.

There were similar differences in the timing of first diagnostic hypothesis. Clinical factors described above partially explain these differences whereas the examining physician factors such as age, gender, experience ... contributed little, suggesting that the personality and methodology of GP matter more. 


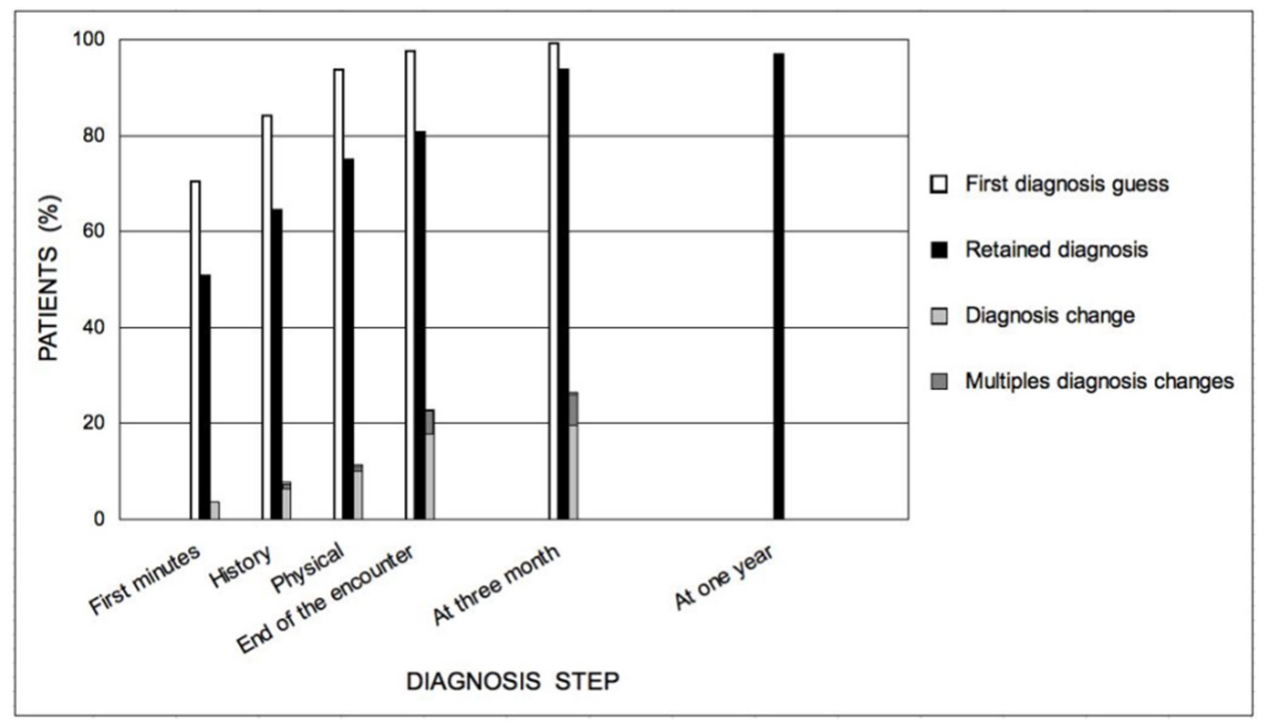

Figure 1: First diagnosis guess and retained diagnosis during the first encounter, at three month and at one year for 672 office patients with chest pain studied in a General Practitioners Network in the French part of Switzerland, during the years 2001-2005. A first diagnosis guess is reported within one to two minutes for $70 \%$ of the patients and does progress during the first encounter and until the third month (white columns). Initial hypothesis can change once or several times for $26.5 \%$ of the patients at one year (greyed columns). Additional diagnosis guesses are made up to one year. At one year the first minute(s) diagnostic hypothesis is confirmed in $51 \%$ patients and at the end of first consultation hypothesis is confirmed in $81 \%$ (black columns). Correct diagnosis progress between the first consultation and the three months step and, less strikingly, between three months and one year.

\section{Importance of the laboratory tests, imaging and specialists}

Diagnostic tests were made in 202 emergency patients (30\%). After the consultation, physicians have asked for additional tests for 193 patients (29\%), a specialised consultation was required for 111 patients (17\%) (Table 2) and thirty-three patients (5\%) were sent to an hospital. A total of 341 patients (50.7\%) did benefit from diagnostic tests. Emergency tests were required more often when a serious condition was suspected, when a diagnosis could not be made and in patients previously unknown to the physician, in emergency consultation, and for anxious patients. They were very helpful: a diagnosis was made significantly more often for such patients by the end of the first consultation. In addition these tests changed the diagnosis of $9.9 \%$ compared to $2.3 \%$ in patients without tests.

Delayed tests were mostly required when a serious condition was suspected, when no diagnosis could be made, when the physician was a woman and/or when the practitioner had less than 3 years of experience. A change in diagnosis resulted respectively in $18.1 \%$ versus $9.4 \%$ at three month. The degree of diagnostic confidence as assessed by the GP rose significantly too. The request for delayed test was not always diagnostic but often for patient or doctor reassurance particularly in psychogenic, parietal, and digestive aetiologies (Table 2).

Specialists (mainly cardiologists) were consulted more often in absence of a diagnosis. Male patients and patients treated by women doctors were more often referred. Female patients with a suspected cardiac condition were referred notably less frequently to a cardiologist than male patients (8). After the specialist evaluation the degree of diagnostic confidence rose significantly.

\section{Aggressive vs. conservative diagnostic strategy}

The diagnostic approach was affected by hypothetic etiology of pain. For example the clinical approach was more aggressive for recently appeared cardiocirculatory chest pain than for recently appeared psychogenic chest pain. Among 46 new cardiac patients, $61 \%$ were diagnosed in the first minute and $89 \%$ at the end of the consultation. For the 48 new patients with psychogenic pain the diagnosis was suspected at the first minute in only $33 \%$ and at the end of the consultation, in $67 \%$ cases. This contrasts strikingly with cardiac cases. Overall, the diagnosis of cardiac disease was wrongly suspected more often than for psychogenic pain.

Additional diagnostic tests were requested more often in patients suspected of having cardiac disease and the reasons for these exams were different. In the cardiac group, tests and referral to specialist were performed mostly for diagnostic purposes, and in the psychogenic group mostly for patient' reassurance (Table 2).

\section{GPs'view}

The GPs assessed at three months the decisive factors leading to their diagnosis. Six clinical key factors were: history $(80 \%$ of patients), physical examination (69\%), prior knowledge of the patient (64\%), initial impression (50\%), evolution (29\%), and a therapeutic trial (21\%). Additional information was obtained by a specialist consultation (15\%), deferred exams (12\%), emergency tests (9\%), and hospital diagnosis (7\%).

In $67 \%$ of cases the primary physician made a diagnosis exclusively by history and physical examination, in $30 \%$ paraclinical tests were added to the clinical impression and in $3 \%$ of cases paraclinical information was the only diagnostic tool.

\section{Weakness and Strength}

There is a long period of time from field study to publication. Nevertheless one could hardly imagine a new very efficient diagnostic tool able to fundamentally change the process. Possible biases are the absence of randomisation to select a representative sample of GPs. The way of doing could be different with a different selection process. Also no monitoring was possible to check that the GPs really enrolled consecutively all patients who reported chest pain, and that questionnaires were really filled in sequence "on the spot".

Finally physicians possibly behaved differently during the initial patient encounter due to the additional paperwork and distraction. However, few studies examined the performance of the sense of danger, of the first diagnostic impression, or timing and diagnostic determinants for patients presenting with a medical problem. Study data were collected from multiple private practices, from a large patient sample size and from a variety of physicians showing a notable adherence quality to the study protocol. 
Table 1: Categorisation of retained diagnosis at one year for 672 office patients with chest pain studied in a General Practitioners Network in the French part of Switzerland, - years 2001-2005.

\begin{tabular}{|c|c|c|c|}
\hline Categories of chest pain & \multicolumn{2}{|c|}{ Specific diagnosis for chest pain } & Complex diagnosis * \\
\hline (\% patients) & Not life threatening & Potentially life threatening & \\
\hline Musculoskeletal chest pain (49\%) & $\begin{array}{l}\text { Chest wall syndrome, trauma, } \\
\text { rib fracture, referred shoulder or } \\
\text { spine pain }\end{array}$ & $\begin{array}{l}\text { Costal metastasis and tumoral } \\
\text { invasion }\end{array}$ & $\begin{array}{l}\text { Costal metastasis and tumoral } \\
\text { invasion }\end{array}$ \\
\hline Cardio-vascular origin (16\%) & $\begin{array}{l}\text { Arrhythmia without circulatory } \\
\text { failure, acute hypertension, aortic } \\
\text { stenosis, mitral prolapse, acute } \\
\text { hypertension }\end{array}$ & $\begin{array}{c}\text { Stable or unstable angina, } \\
\text { myocardial infarcts, arrythmia } \\
\text { with instable circulatory state, } \\
\text { pulmonary embolism }\end{array}$ & $\begin{array}{l}\text { Cardiomyopathy, acute } \\
\text { hypertension, arrythmia }\end{array}$ \\
\hline Psychogenic chest pain (11.5\%) & $\begin{array}{c}\text { Anxious state, acute anxiety and } \\
\text { panic attack, anxio-depression, } \\
\text { somatoform disorder }\end{array}$ & - & Somatoform disorder \\
\hline Respiratory origin (10.5\%) & Bronchitis, asthma, COPD & $\begin{array}{c}\text { Pneumonia, pleurisy, acute } \\
\text { asthma }\end{array}$ & $\begin{array}{l}\text { Pulmonary abscess, pulmonary } \\
\text { cancer }\end{array}$ \\
\hline Digestive origin (8\%) & $\begin{array}{l}\text { Peptic affection: esophagitis, } \\
\text { gastritis, gastric ulcer } \\
\text { oesophageal spasm }\end{array}$ & $\begin{array}{l}\text { Oesophageal cancer, pancreatic } \\
\text { cancer, acute cholecystitis }\end{array}$ & $\begin{array}{l}\text { Oesophageal spasm, acute } \\
\text { cholecystis, digestive cancers }\end{array}$ \\
\hline Miscellaneous (2\%) & $\begin{array}{l}\text { Mastitis, mastalgia, herpes zoster, } \\
\text { skin infection, chest wall keloid, } \\
\text { sarcoidoisis }\end{array}$ & Acute pyelonephritis & $\begin{array}{l}\text { Sarcoidosis } \\
\text { Acute pyelonephritis }\end{array}$ \\
\hline Without diagnosis (3\%) & - & - & - \\
\hline
\end{tabular}

* complex diagnoses are specific diagnoses with difficult clinical problem solving necessitating complementary investigation or diagnoses retained after a process of exclusion.

Table 2: Emergency and delayed diagnostic tests and reference to specialists for 672 office patients with chest pain studied in a General Practitioners Network in the French part of Switzerland, - years 2001-2005.

\begin{tabular}{|c|c|c|c|c|c|c|}
\hline $\begin{array}{l}\text { Categories of } \\
\text { chest pain }\end{array}$ & $\mathbf{n}$ & $\begin{array}{c}\text { Emergency } \\
\text { diagnostic tests } \\
\text { n (\%) }\end{array}$ & $\begin{array}{c}\text { Delayed } \\
\text { diagnostic tests } \\
\mathbf{n}(\%)\end{array}$ & $\begin{array}{l}\text { Most frequent } \\
\text { mentioned goal }\end{array}$ & $\begin{array}{c}\text { Specialists 1) and } \\
\text { specialized tests 2) } \\
\text { n (\%) }\end{array}$ & $\begin{array}{l}\text { Most frequent } \\
\text { expectation from } \\
\text { specialist }\end{array}$ \\
\hline $\begin{array}{l}\text { Musculoskeletal } \\
\text { chest pain }\end{array}$ & 331 & $87(26)$ & $88(27)$ & Patient reassurance & $31(9)$ & $\begin{array}{l}\text { Preclude an } \\
\text { affection }\end{array}$ \\
\hline $\begin{array}{l}\text { Cardio-vascular } \\
\text { origin }\end{array}$ & 108 & $37(34)$ & $37(34)$ & Diagnosis & $37(34)$ & Diagnosis \\
\hline $\begin{array}{l}\text { Psychogenic chest } \\
\text { pain }\end{array}$ & 77 & $21(27)$ & $14(18)$ & $\begin{array}{l}\text { Patient reassurance } \\
\text { Preclude an affection }\end{array}$ & $12(16)$ & $\begin{array}{l}\text { Preclude an } \\
\text { affection }\end{array}$ \\
\hline Respiratory origin & 71 & $32(45)$ & $25(35)$ & Diagnosis & $7(10)$ & $\begin{array}{c}\text { Diagnosis } \\
\text { Doctor reassurance }\end{array}$ \\
\hline Digestive origin & 55 & $16(29)$ & $17(31)$ & $\begin{array}{l}\text { Preclude an affection } \\
\text { Patient reassurance }\end{array}$ & $16(29)$ & Diagnosis \\
\hline Without diagnosis & 21 & $8(38)$ & $10(48)$ & Preclude an affection & $7(33)$ & $\begin{array}{l}\text { Preclude an } \\
\text { affection }\end{array}$ \\
\hline Miscellaneous & 9 & $1(11)$ & $2(22)$ & - & $0 \quad(0)$ & - \\
\hline Total & 672 & $202(30)$ & $193(29)$ & Preclude an affection & $111(17)$ & Diagnosis \\
\hline
\end{tabular}

1) 130 specialist references for 111 patients: cardiology 79 ; gastroenterology 28 ; pneumology 11 ; rheumatology 8 ; psychiatry 2 ; neurology 1 .

2) Ergometry and stress echocardiography 51; coronaro-/scintigraphy 18; cardiac echography 15; Holter 5; gastroscopy 25 ; other 7. 


\section{Discussion}

The observation "on the spot" of the diagnostic process followed by experienced GPs facing patients with chest pain reveals the following facts: (1o) the assessment of a critical case is made very quickly; (2o) an early diagnostic guess is most often made after the first minutes of the patient's complaint; (3o) an analytical process starts soon after the initial hypothesis and can continue until the end of the consultation and beyond; (4o) this diagnostic approach is common to all physicians.

The GPs face thoracic pain with an assessment of the danger it represents within the first minutes in the majority of patients. At this very early stage of the consultation, risk identification is necessarily based on very little objective data: a short history, physical examination limited to general signs, body language, etc. Others have recently described such a sense of danger in general practice as "an uneasy feeling perceived by a GP as he/she is concerned about a possible adverse outcome, even though specific indications are lacking" $[9,10]$. The GPs suspect more dangerous conditions that will finally be confirmed (the "precautionary principle"). Sensibility and specificity for the prediction of acuity at the first minutes are relatively high and comparable to the values reported in a Department of Emergency Medicine [11].

The first diagnostic hypotheses are also made very quickly and are unchanged at one year in half of all patients. Thus the final diagnosis is obvious "at first glance" for one out of two patients [7]. This early diagnostic hypothesis is mostly based on weak non-verbal signals $[5,12]$. The hazard assessment and early diagnostic hypothesis are dependent on intuition. Intuition can be defined as an ability to acquire knowledge without inference or the use of reason. T. Greenhalgh best described the key feature of intuition in diagnosis as" - a rapid, unconscious process; - context-sensitive; - comes with practice; - involves selective attention to small details; - cannot be reduced to cause-and-effect-logic; - addresses, integrates, and makes sense of multiple complex pieces of data" [1]. The psychological anthropologists interested in the evolution of human thought suggests that at an early period, it was vital for mankind to develop systems for rapid and effective assessment of danger [14,15], to judge reliability and health status of clan members and non-members by incomplete communication elements $[16,17]$. Thus intuitive medical diagnosis could be the heir to neocortical inference systems working unconsciously and very rapidly with the help of (hypothetical) mirror neurons $[18,19]$. Let us accept that the diagnostic process depends on a phylogenetic mechanism witch appeared early in evolution. So it may be independent of ethnic, cultural, socioeconomic and medical considerations.

A high success rate shows the efficiency of the intuitive process, but the initial diagnostic hypothesis is corrected in one in four patients, showing its limits $[1,20]$. It is delayed when the diagnosis is complex, or new, or when the patient was previously unknown, and mostly by emotional factors such as patient' or the physician's anxiety $[17,21,22]$.

In the case of complex problem solving presented to an expert, A. Elstein noted that 3-4 diagnostic hypotheses are discussed immediately followed by others related to tests $[1,23]$. The initial assumption is the starting point of an analytical process further refined by more complete data. J. Kassirer suggests that an hypotheticodeductive approach is preferably chosen by less experienced doctors or when the early pattern recognition fails [24]. Our observations agree with those of Elstein and of Kassirer. The GPs are aware of their intuitive approach and its limits [25] and there is a cognitive continuity from what Croskerry called informal / intuitive to computable / analytical process $[26,27]$ which is shown in the present study by the process of rapid intuitive diagnostics either maintained, corrected, or abandoned later.

What is the contribution of laboratory tests and imaging $[28,29]$ ? Previous publications suggest that the majority of diagnoses in general practice is made without paraclinical data $[30,31]$ even in an academic center $[32,33]$. However, these publications predate the impressive progresses of medical technology. Obviously the severity of diagnoses and complex diagnoses cannot dispense with today's reliable paraclinical investigations but such cases are not the most frequent in daily practice of most GPs. In our study, half of patients with chest pain did not require diagnostic tests. For cases that have provided such information, the gain in terms of diagnoses or diagnostic safety is significant and similar to what has been shown in previous studies $[34,35]$. The need to clarify the risk and the diagnosis does not explain, however, all of the examinations carried out: we also notice an emotional motivation such as patient anxiety, the desire to reassure him, physician's gender and style, as well as patient gender. Other characteristics such as other emotional problems $[5,36,37]$, communication problems $[5,22]$, the requirements of patients $[22,38,39]$, legal protection, economic incentive etc. have been described. For all these reasons it is difficult to evaluate the contribution of laboratory and imaging tests to the diagnosis. In any event, a revolutionary paraclinical examination or innovating clinical prediction rule could hardly change the diagnostic approach since it would be valuable after the initiation of diagnostic approach only. Ultimately, evaluating the danger of disease, starting diagnostic assumptions, deciding the need for tests, and integrating the whole into the global picture remains the ultimate clinical process that will benefit from further progress diagnostic tests without being supplanted by them. As the diagnostic approach in general practice is based on the clinic, the medical training has to enable the accumulation of clinical experience fundamental to develop intuitive approach. It also has to complete the skills in history-taking, physical examination and communicating with a patient [40].

\section{Acknowledgment}

We thank MD Lilli Herzig, Bernard Burnand, and Bernard Favrat, the principal co-investigators of the TOPIC study, Françoise Secretan for her precious task as coordinative scientific nurse and our colleagues from the General Practitioners Network for data, counselling and clinical contribution: Marc Abdelmoula, James Alexander, Jean-Marc Bidaux, Michel Bidlingmeyer, Thomas Bischoff, Corine Bonard, Marc Bonard, Jean-Luc Bourban, Jean-Paul Bussien, Christophe Chapuis, François Chuard, Georges Conne, Christian Cuendet, Michel Daflon, Marco Danese, Maryse de Vevey, Janine Dumas, Charles Dvorak, Michel Eddé, Juerg Eidenbenz, Philippe Erard, Véronique Gerber Genier, Willy Gilgien, Bernard Giorgis, Michel Graff, Lilli Herzig, Thierry Horn, Pierre-Yves Jaquet, Sébastien Jotterand, Michel Junod, Laurent Kaufmann, Abel Lanaspa, Raymond Larpin, Claude Matthey, Alain Michaud, Gianni Minghelli, Rafael Morales, Nicole Muhlemann, Andrea Mueller, François Murisier, Marie-Amélie Pernet, Raymond Pernet, François Pilet, Olivier Pyroth, Luc Robyn, Olivier Rubli, Pierre-Alain Schmied, Alain Schwob, Jacques Sommer, Jean-Paul Studer, Etienne Urfer, Pascal Valotton, Jean-Pierre Voegeli, Yves-Marie Wasem, Marc Wenner, Pierre Widmer, Claude Yersin and, at the Department of ambulatory Care and Community Medicine: Muriel Blanc, Albert Burki, Barbara Chiesi, Gabrielle de Torrenté, Isabelle Marguerat, and Roxane Selz.

\section{Funding}

The Swiss Academy of Medical Sciences allocated a grant supporting the TOPIC study (Thoracic pain in community) which includes the present research.

The study protocol was approved by the official Ethical Commission of Internal Medicine, faculty of Medicine, Lausanne, Switzerland (Prot. 41/2000).

\section{References}

1. Elstein AS, Schwartz A. Clinical problem solving and diagnostic decision making: selective review of the cognitive literature. BMJ 2002;324:729-32.

2. Le Gal G, Righini M, Roy PM, Sanchez O, Aujesky D, Bounameaux H, et al. Prediction of pulmonary embolism in the emergency department: the revised Geneva score. Ann Intern 
Med 2006;144:165-71

3. Tracy CS, Dantas GC, Moineddin R, Upshur RE. The nexus of evidence, context, and patient preferences in primary care: postal survey of Canadian family physicians. BMC Fam Pract 2003;4:13-21.

4. Elstein AS. Clinical problem solving and decision psychology: comment on "the epistemology of clinical reasoning". Acad Med 2000;75:S134-6.

5. Bruyninckx R, Van den Bruel A, Hannes K, Buntinx F, Aertgeerts B. GPs' reasons for referral of patients with chest pain: a qualitative study. BMC Fam Pract 2009;10:55-62.

6. Stolper E, van Bokhoven M, Houben P, Van Royen P, van de Wiel $M$, van der Weijden $T$, et al. The diagnostic role of gut feelings in general practice. A focus group study of the concept and its determinants. BMC Fam Pract 2009;10:17-25.

7. Verdon F, Junod M, Herzig L, Vaucher P, Burnand B, Bischoff T, et al. Predictive ability of an early diagnostic guess in patients presenting with chest pain; a longitudinal descriptive study. BMC Fam Pract 2010;11:14-18.

8. Clair C, Vaucher P, De Francesco T, Jaunin-Stalder N, Herzig L, Verdon F, et al. Sex differences in the management of chest pain of cardiovascular origin in ambulatory care. PrimaryCare 2014;14:224. Abstract

9. Stolper E, Van Royen P, Van de Wie M, Van Bokhoven M, Houben P, Van der Weijden T, et al. Consensus on gut feelings in general practice. BMC Fam Pract 2009;10:66-71.

10. Hjertholm P, Moth G, Ingeman ML, Vedsted P. Predictive values of GPs' suspicion of serious disease: a population-based follow-up study. Br J Gen Pract. 2014;64:e346-e353

11. Wiswell J, Tsao K, Bellolio MF, Hess EP, Cabrera D. "Sick" or "not-sick": accuracy of System 1 diagnostic reasoning for the prediction of disposition and acuity in patients presenting to an academic ED. Am J Emerg Med 2013;31:1448-52.

12. Mast MS. On the importance of nonverbal communication in the physician-patient interaction. Patient Educ Couns 2007;67:315-8.

13. Greenhalgh $\mathrm{T}$. Intuition and evidence--uneasy bedfellows? $\mathrm{Br} \mathrm{J}$ Gen Pract 2002;52:395-400.

14. Boyer P. Et l'homme créa les dieux : Comment expliquer la religion. Robert Laffont, Paris; 2001

15. Herrmann E, Call J, Hernandez-Lloreda MV, Hare B, Tomasello M. Humans have evolved specialized skills of social cognition: the cultural intelligence hypothesis. Science 2007;317:1360-6.

16. Cosmides L, Barrett HC, Tooby J. Adaptive specializations, social exchange, and the evolution of human intelligence. Proc Natl Acad Sci USA 2010;107 Suppl 2:9007-14.

17. Singer T, Seymour B, O'Doherty JP, Stephan KE, Dolan RJ, Frith $\mathrm{CD}$. Empathic neural responses are modulated by the perceived fairness of others. Nature 2006;439:466-9.

18. Rizzolatti G, Fabbri-Destro M, Cattaneo L. Mirror neurons and their clinical relevance. Nat Clin Pract Neurol 2009;5:24-34.

19. Bauer J. Warum ich fühle, was du fühlst. Intuitive kommunikation und das Geheimnis der Spiegelneurone; Hoffmann und Campe, Hamburg, 2006.

20. Hall KH. Reviewing intuitive decision-making and uncertainty: the implications for medical education. Med Educ 2002;36:21624 .
21. Roter DL, Frankel RM, Hall JA, Sluyter D. The expression of emotion through nonverbal behavior in medical visits. Mechanisms and outcomes. J Gen Intern Med 2006; 21 Suppl 1:S28-34.

22. Birdwell BG, Herbers JE, Kroenke K. Evaluating chest pain. The patient's presentation style alters the physician's diagnostic approach. Arch Intern Med 1993;153:1991-5.

23. Elstein AS. Thinking about diagnostic thinking: a 30-year perspective. Adv Health Sci Educ Theory Pract 2009;14 Suppl 1:7-18.

24. Kassirer JP, Kopelman RI. Learning Clinical Reasoning. Williams and Wilkins, Baltimore; 1991.

25. Barraclough K. Medical intuition. BMJ 2006;332:497.

26. Croskerry P. A universal model of diagnostic reasoning. Acad Med 2009;84:1022-8.

27. Werner M. A model for medical decision making and problem solving. Clin Chem 1995;41:1215-22.

28. Bordage G. Where are the history and the physical? CMAJ 1995; 152:1595-8.

29. Martina B, Bucheli B, Stotz M, Battegay E, Gyr N. First clinical judgment by primary care physicians distinguishes well between nonorganic and organic causes of abdominal or chest pain. J Gen Intern Med 1997;12:459-65.

30. Boland BJ, Wollan PC, Silverstein MD. Review of systems, physical examination, and routine tests for case-finding in ambulatory patients. Am J Med Sci 1995;309:194-200.

31. Peterson MC, Holbrook JH, Von Hales D, Smith NL, Staker LV. Contributions of the history, physical examination, and laboratory investigation in making medical diagnoses. West J Med 1992;156:163-5.

32. Reilly BM. Physical examination in the care of medical inpatients: an observational study. Lancet 2003;362:1100-5.

33. Fitzgerald FT. Physical diagnosis versus modern technology. A review. West J Med 1990;152:377-82.

34. Fukui T. Relative contribution of history-taking, physical examination, and stat laboratory test to diagnosis in chest pain patients. Nippon Koshu Eisei Zasshi 1990;37:569-75.

35. Crosskerry P, Abbass, A, Wu, A. How Doctors Feel: Affective Issues in Patient Safety. Lancet 2008;372:1205-06.

36. Singer T. The neuronal basis and ontogeny of empathy and mind reading: review of literature and implications for future research. Neurosci Biobehav Rev 2006;30:855-63.

37. Farmer SA, Roter DL, Higginson IJ. Chest pain: communication of symptoms and history in a London emergency department. Patient Educ Couns 2006;63:138-44.

38. Little P, Dorward M, Warner G, Stephens K, Senior J, Moore M. Importance of patient pressure and perceived pressure and perceived medical need for investigations, referral, and prescribing in primary care: nested observational study. BMJ 2004;328:444-6.

39. Tracy CS, Dantas GC, Upshur RE. Evidence-based medicine in primary care: qualitative study of family physicians. BMC Fam Pract 2003;4:6-14.

40. Verghese A, Brady E, Kapur CC, Horwitz RI. The beside evaluation: ritual and reason. Ann Intern Med 2011;155:550-53. 